\title{
Elektrolitik Sert Metal Kaplamaya Alternatif Çevreye Duyarlı Ni-P Kaplamaların 6061 Serisi Alüminyum Altlık Üzerine Akımsız Yöntemle Biriktirilmesinde Sodyum hipofosfit, Sıcaklık ve Zamanın Etkisi
}

\author{
*1 Abdulkadir Akyol, ${ }^{1}$ Hasan Algül, ${ }^{1}$ Oğuzhan Bilaç, ${ }^{1}$ Seda Ulu, ${ }^{2}$ Harun Gül, ${ }^{1}$ Mehmet Uysal, ${ }^{3}$ Yusuf Çay, ${ }^{1}$ Ahmet Alp \\ ${ }^{1}$ Mühendislik Fakültesi, Metalurji ve Malzeme Mühendisliği, Sakarya Üniversitesi, Sakarya, 54187, Türkiye \\ ${ }^{2}$ Makine ve Metal Teknolojileri Bölümü, Gümüş̧ova Meslek Yüksekokulu, Düzce Üniversitesi, Düzce, 81850, Türkiye \\ ${ }^{3}$ Teknoloji Fakültesi, Makina Mühendisliği, Sakarya Üniversitesi, Sakarya, 54187, Türkiye \\ * abdulkadir.akyol1@ogr.sakarya.edu.tr
}

Araştırma Makalesi

Geliş Tarihi: 03.11.2018

Kabul Tarihi: 19.03.2019

Öz

Elektrolitik kaplamalara alternatif oluşturan ve dışarıdan herhangi bir elektrik ihtiyacına gerek duymadan gerçekleşen otokatalitik akımsız kaplamalar birçok endüstriyel alanda kullanılmaktadır. Homojen bir kaplama kalınlığı elde edilmesi, yüksek sertlik, iyi korozyon ve aşınma direncine sahip olması, akımsız kaplamaları oldukça yaygın hale getirmektedir. Ayrıca karmaşık şekilli parçalara da uygulanabilmesi avantajları arasında yer almaktadır. Bu çalışmada akımsız Ni-P kaplamaların sertlik, metalik nikel ve fosfor içerikleri, 1sıl işlem sonrası oluşan bileşik türleri ve mikroyapısal özellikleri incelenerek sodyum hipofosfit, sicaklık ve zaman parametrelerinin etkileri ortaya konmuştur.

Anahtar Kelimeler: Akımsız nikel kaplama, sodyum hipofosfit, sıcaklık, zaman

\section{The Effect of Sodium Hypophosphite, Temperature and Time in co-deposit Ni-P Coatings on 6061 Series Aluminum Substrate: An Environment-Friendly Alternative to Electrolytic Hard Metal Coatings}

\footnotetext{
*11Abdulkadir Akyol, ${ }^{1}$ Hasan Algül, ${ }^{1}$ Oğuzhan Bilaç, ${ }^{1}$ Seda Ulu, ${ }^{2}$ Harun Gül, ${ }^{1}$ Mehmet Uysal, ${ }^{3}$ Yusuf Çay, ${ }^{1}$ Ahmet Alp

${ }^{1}$ Faculty of Engineering, Metallurgy and Materials Engineering, Sakarya University, Sakarya, 54187, Turkey

${ }^{2}$ Machine and Metal Technology Department, Gumusova Vocational School, Duzce University, Duzce, 81 850, Turkey

${ }^{3}$ Faculty of Technology, Mechanical Engineering, Sakarya University, Sakarya, 54187, Turkey
}

\begin{abstract}
The autocatalytic electroless depositions, which form an alternative to the electrolytic deposition and do not require any external electrical power, are used in many industrial areas.Electroless nickel based plating has increased attention because of their excellent corrosion, wear, thermal and electrical properties. They also offer good magnetic properties. Because of their high mechanical properties electroless nickel coating are used in many areas. Many commercial coatings have been experimented and it is easiest use nickel phosphorus, which is one of the most common. In study electroless nickel phosphorus coating the effect of sodium hypophosphite, bath temperature and bath time amount on morphology and properties of the coating was examined.
\end{abstract}

Keywords: Electroless nickel coating, sodium hydrophosphite, temperature, time

1. GíRiş

*Sorumlu Yazar: Mühendislik Fakültesi, Metalurji ve Malzeme Mühendisliği, Sakarya Üniversitesi, Sakarya, 54187, Türkiye, abdulkadir.akyol1@ogr.sakarya.edu.tr, +905315235588
Akımsız nikel kaplama, çözeltideki nikel iyonlarının nötr metalik nikele indirgenmesini sağlayan kimyasal bir işlemdir 
[1]. Akımsız nikel kaplamalar nikel-fosfor, nikel-bor ve saf nikel kaplamalar şeklinde üç ana gruba ayrılabilir [2]. Akımsız nikel kaplamalar indirgeyici ajana göre gruplandırıldığında nikel fosfor kaplamalar için hipofosfitler, nikel bor kaplamalar için amino boranlar ve borhidrürler, saf nikel kaplamalar için ise hidrazin redükleyici olarak kullanılır. En yaygın kullanılan indirgeyici sodyum hipofosfittir [2]. Hidrazin kullanılmasıyla neredeyse saf nikelin otokatalitik olarak birikimi sağlanabilmektedir [3].

Ni-P kaplama yapısında değişiklik gösteren fosfor miktarına göre kaplama özellikleri de farklılık gösterir. Kendi içlerinde düşük (\%1-3), orta (\%4-10) ve yüksek (\%11-13) fosforlu kaplamalar olarak sinıflandırılabilir ve kaplama özellikleri yapıdaki fosfor miktarı ile doğrudan bağlantılıdır [4]. Akımsız Ni-P kaplama tekniği yüksek aşınma direnci, iyi yağlanabilirlik ve yüksek sertlik gibi özelliklere sahip olduğu için birçok alanda kullanılır [5-9]. Düşük fosfor içerikli (1-3 $\%$ P) kaplama kristalin olup iyi bir aşınma direnci fakat klorürlü ortamda düşük korozyon direnci sağlar. Orta derecede fosfor içeren kaplama (4-10 \% P) daha küçük kristal boyutlara sahiptir ve yarı amorf eğilimi gösterir. Halbuki yüksek fosfor içeren (\% 11'den daha fazla) kaplamalar metalik cam gibi davranırlar. Akımsız nikel kaplamaların yoğunluğu fosfor içeriğinden ters oranda etkilenmektedir. Düşük fosforlu kaplamalarda yoğunluk 8,5 $\mathrm{gr} / \mathrm{cm}^{3}$ iken $\% 10-11$ fosfor içeriklilerde $7,75 \mathrm{gr} / \mathrm{cm}^{3}$ civarına düşer. Termal ve elektrik özellikleri de kaplamanın bileşiminden etkilenir. Kaplamaların iletkenliği bakır gibi geleneksel iletkenlere göre düşüktür. Buna rağmen 1sıl işlemlerle kaplamaların iletkenliği 3-4 kat artırılabilir. Ni-P kaplamalar düşük sürtünme katsayısına sahip olup yapışma göstermezler. Kaplamaların sertlik değerleri oldukça yüksektir ve 1sıl işlem ile bu değerlerde artışlar meydana gelir [10].

\section{MALZEME VE YÖNTEM}

Deneysel çalışmalarda Akımsız nikel kaplanacak malzeme olarak $50 \mathrm{~mm} \times 30 \mathrm{~mm} \times 2 \mathrm{~mm}$ boyutlarında 6061 serisi alüminyum altlıklar kullanılmıştır. Akımsız nikel kaplama yapılmadan önce altlıklar sirasıyla 120, 240, 400, 600, 800, 1000 ve 1200 'lük SiC zımparalarla zımparalandıktan sonra yüzeyleri parlatılmıştır. Daha sonra asidik bir banyo içerisinde yüzeyinde bulunabilecek yağ, kir ve oksit tabakası giderilmiştir. Malzeme yüzey kirliliklerinin giderilmesi için aşağıda işlem aşamalarında belirtilen ön temizleme işlemi uygulanmış numuneler, ticari zinkat banyosuna daldırılmıştır. $\mathrm{NiSO}_{4}$ içeren ticari zinkat çözeltisine daldırma yöntemi ile iki adımda gerçekleştirilmiştir. Yüzey temizlemeden kaplamaya kadar tüm gerçekleştirilen işlem adımları aşağıdaki gibidir:

- Asidik temizleme(10ml/1 sülfürik asit, $12,5 \mathrm{ml} / \mathrm{l}$ hidroflorik asit, $25 \mathrm{ml} / \mathrm{l}$ nitrik asit)

- Durulama (saf su ile)

- Zinkatlama İşlemi (Ticari zinkat kullanılmıştır.)

- Akımsız nikel kaplama (Ni-P)
- Tüp firında 1 sıl işlem $\left(400^{\circ} \mathrm{C}\right.$ sıcaklıkta 2 saat süreyle $\mathrm{Ar}-\% 5 \mathrm{H}_{2}$ gazı atmosferinde)

- Oda sicaklığına soğutma.

Taramalı elektron mikroskobu (SEM) yardımıyla kaplama tabakasının yüzey görüntüleri alınarak ısıl işlem öncesi ve sonrası kaplama tabakasında meydana gelen değişimler tespit edilmiştir. EDS ile kaplamalarda elementel fosfor da analiz edilerek morfolojideki dağılımı da tespit edilmiştir. Kaplama tabakasının bileşimini ve ısıl işlem sonucu kaplama tabakasında meydana gelen faz değişimleri Rigaku D/MAX 2000 marka XRD cihazı ile belirlenmiştir. X-1şınları analizi bakır tüp $(\lambda=1,5418 \mathrm{~A})$ kullanılarak gerçekleştirilmiştir. X1şınları taraması $10^{\circ}$ ile $90^{\circ}$ arasında $2^{\circ} / \mathrm{dk}^{\prime} \mathrm{l} 1 \mathrm{k}$ hızla gerçekleştirilmiştir. Isıl işlem görmemiş numunelerle ısıl işlem görmüş bütün numunelerin XRD paternleri alınarak yapıdaki değişimler incelenmiş, 1 sıl işlem sonrası yapıdaki $\mathrm{Ni}_{3} \mathrm{P}$ vb. bileşiklerinin oluşup oluşmadığı tespit edilmiştir. Akımsız kaplama sonrası farklı numuneler için mikrosertlik değerleri Leica VMHT marka cihazla ölçülmüştür. 25 gr'lık yükler uygulanarak bir numuneye en az 5 ölçüm yapılmış ve ortalamaları Vickers sertlik değeri olarak alınmıştır. Isıl işlem görmüş numuneler ile görmemiş numunelerin sertlik değerlerindeki farklılıklar tespit edilmiştir.

\section{DENEYSEL SONUÇLAR VE TARTIŞMA}

\subsection{Akımsız Ni-P Kaplamaların Sodyum Hipofosfit Oranı Etkisi}

Akımsız Ni-P kaplamalara $\mathrm{NaPO}_{2} \mathrm{H}_{2}$ (sodyum hipofosfit) oranının etkisi incelenmiş olup Tablo 1.'de banyo bileşimi verilmektedir. $\mathrm{NaPO}_{2} \mathrm{H}_{2}$ oranının artışıly birlikte kaplamalarda meydana gelen morfoloji değişimleri ve kaplama kalınlıklarını incelemek için SEM, faz yapısındaki değişimler için XRD ve sertlik özellikleri için mikrosertlik değerlerine bakılmış olup bu deneyler sonucunda en iyi $\mathrm{NaPO}_{2} \mathrm{H}_{2}$ oranı seçilmiştir.

Tablo 1. Kaplama banyosunun sodyum hipofosfit ve diğer kimyasalların içeriği ve parametrelerin değişimi.

\begin{tabular}{|l|c|c|c|c|c|}
\hline $\begin{array}{l}\text { Banyo } \\
\text { Bileşenleri }\end{array}$ & $\mathbf{A 1}$ & $\mathbf{A 2}$ & $\mathbf{A 3}$ & $\mathbf{A 4}$ & $\mathbf{A 5}$ \\
\hline $\begin{array}{l}\mathrm{NiSO}_{4} \cdot 6 \mathrm{H}_{2} \mathrm{O} \\
(\mathrm{g} / \mathrm{L})\end{array}$ & 28 & 28 & 28 & 28 & 28 \\
\hline $\begin{array}{l}\mathbf{N a P O}_{2} \mathrm{H}_{2} \\
(\mathrm{~g} / \mathrm{L})\end{array}$ & $\mathbf{1 0}$ & $\mathbf{2 0}$ & $\mathbf{3 0}$ & $\mathbf{4 0}$ & $\mathbf{5 0}$ \\
\hline $\begin{array}{l}\mathrm{C}_{2} \mathrm{H}_{3} \mathrm{NaO}_{2} \\
(\mathrm{~g} / \mathrm{L})\end{array}$ & 35 & 35 & 35 & 35 & 35 \\
\hline $\begin{array}{l}\mathrm{C}_{3} \mathrm{H}_{6} \mathrm{O}_{3} \\
(\mathrm{ml} / \mathrm{L})\end{array}$ & 20 & 20 & 20 & 20 & 20 \\
\hline $\mathrm{pH}$ & $4-5$ & $4-5$ & $4-5$ & $4-5$ & $4-5$ \\
\hline Süre $(\mathrm{dk})$ & 30 & 30 & 30 & 30 & 30 \\
\hline Sicaklik $\left({ }^{\circ} \mathrm{C}\right)$ & 90 & 90 & 90 & 90 & 90 \\
\hline
\end{tabular}

Tablo 1'de akımsız Ni-P banyosunun bileşenleri verilmiştir. Tüm bileşenler sabit bırakılıp indirgeyici ve $\mathrm{P}$ kaynağı olarak kaplamalar üzerindeki etkisini incelemek için $\mathrm{NaPO}_{2} \mathrm{H}_{2}$ farklı konsantrasyonlarda $(10,20,3040$ ve $50 \mathrm{~g} / \mathrm{L})$ dahil edilmiştir. 


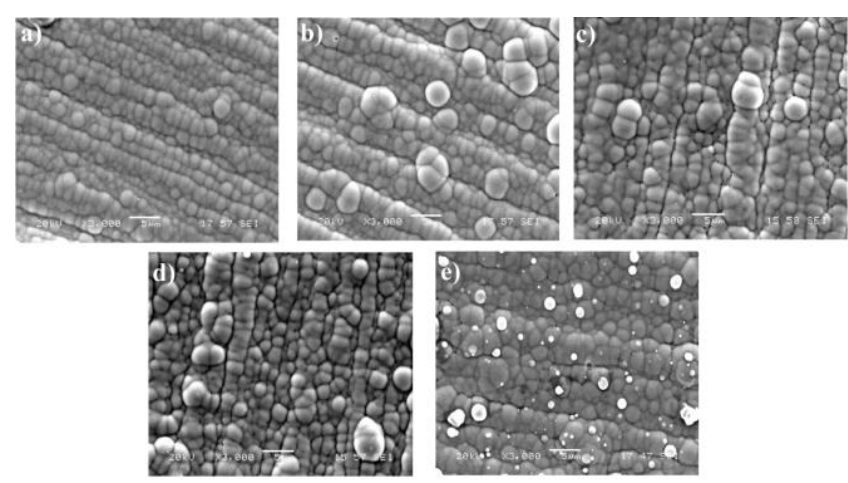

Şekil 1. Kaplama banyosundaki sodyum hipofosfit oranının etkisi a) A1 (10 g/L NaPO$\left.{ }_{2} \mathrm{H}_{2}\right)$ b) $\mathrm{A} 2\left(20 \mathrm{~g} / \mathrm{L} \mathrm{NaPO} \mathrm{H}_{2}\right)$ c) A3 $\left(30 \mathrm{~g} / \mathrm{L} \mathrm{NaPO} \mathrm{H}_{2}\right)$ d) A4 $\left(40 \mathrm{~g} / \mathrm{L} \mathrm{NaPO}_{2} \mathrm{H}_{2}\right)$ ve e) A5 (50 $\left.\mathrm{g} / \mathrm{L} \mathrm{NaPO} \mathrm{H}_{2}\right)$

Şekil 1.'de akımsız Ni-P kaplamaların $\mathrm{NaPO}_{2} \mathrm{H}_{2}$ (sodyum hipofosfit) oranına bağlı olarak SEM görüntüleri verilmektedir. Şekil 1'den de görüldüğü gibi sodyum hipofosfit oranı arttıkça tane sınırları iyice azalmıştır ve daha düz bir yüzey elde edilmiştir. $10 \mathrm{~g} / \mathrm{L} \mathrm{NaPO}_{2} \mathrm{H}_{2}$ oranına sahip kaplamada (A1) ince taneler ve tane sınırları açıkça görülmektedir. $30 \mathrm{~g} / \mathrm{L} \mathrm{NaPO}{ }_{2} \mathrm{H}_{2}$ (A3) oranında ise taneler giderek kabalaşmaya ve tane sınırları azalmaya başlamıştır. $50 \mathrm{~g} / \mathrm{L} \mathrm{NaPO} \mathrm{H}_{2}$ oranına sahip kaplamada (A5) ise tane sınırları iyice azalmıştır.

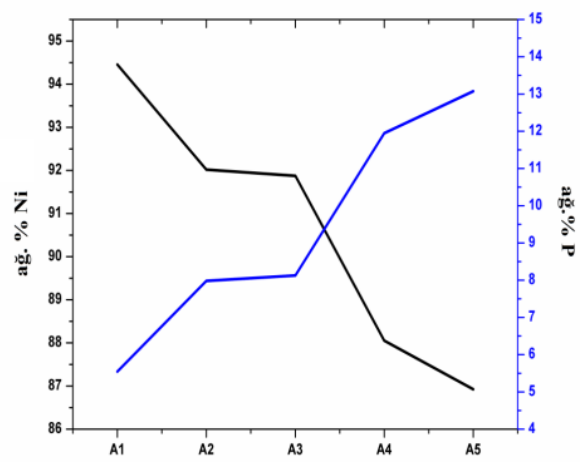

Şekil 2. Sodyum hipofosfit miktarına bağlı olarak kaplamaların Ni ve P \%si, A1 (10 g/L NaPO$\left.{ }_{2} \mathrm{H}_{2}\right)$, A2 (20 g/L $\left.\mathrm{NaPO}_{2} \mathrm{H}_{2}\right), \mathrm{A} 3\left(30 \mathrm{~g} / \mathrm{L} \mathrm{NaPO}_{2} \mathrm{H}_{2}\right), \mathrm{A} 4\left(40 \mathrm{~g} / \mathrm{L} \mathrm{NaPO}{ }_{2} \mathrm{H}_{2}\right)$ ve A5 $\left(50 \mathrm{~g} / \mathrm{L} \mathrm{NaPO} \mathrm{H}_{2}\right)$.

Numunelerin EDS analiziyle elde edilmiş grafiğe göre kaplama banyosundaki sodyum hipofosfit oranı arttıkça kaplama içindeki elementel P oranı artmaktadır. Elde edilen sonuçları literatür ile karşılaştırdığımız zaman, ağırlıkça \% 1 5 fosfor içeren (düşük fosforlu) akımsız nikel kaplamalarının mikro yapıları kristal haldedir. Ağırlıkça \% 6-9'u fosfor içeren (orta fosfor) kaplamalar karışık kristalimsi ve amorf yapıdadır. Buna karşın ağırlıç̧a \% 10-13 fosfor (yükssek fosfor) içeren kaplamalar amorf yapıda oluşurlar [2]. En yüksek P \% sine, $50 \mathrm{~g} / \mathrm{L}$ sodyum hipofosfit kullanıldığında ulaşılmıştır (\%13,075 elementel P). Ancak yüksek P içeriklerine hem A4 hem de A5 banyosu ile ulaşılabildiği gözlenmiştir.
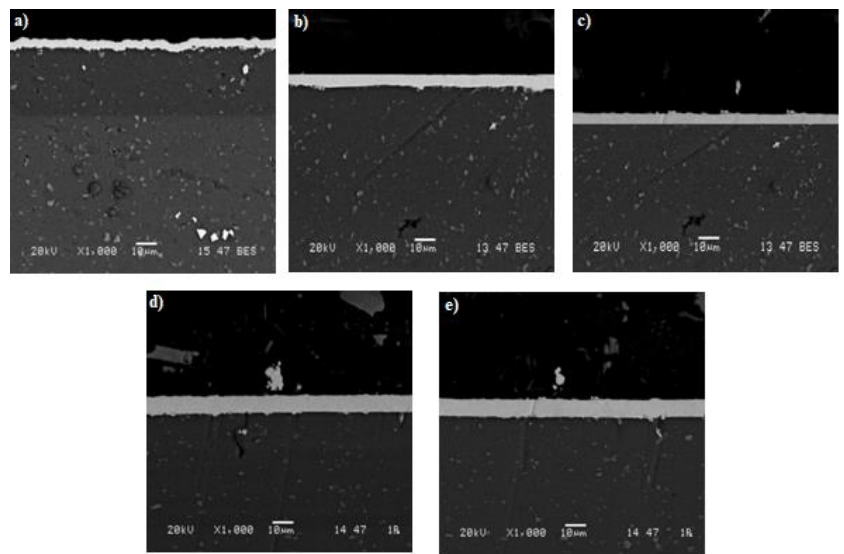

Şekil 3. Farklı oranda redükleyiciyle oluşan kaplamaların kesitleri a)A1 (10 g/L NaPO$\left.{ }_{2} \mathrm{H}_{2}\right)$, b)A2 (20 g/L NaPO$\left.{ }_{2} \mathrm{H}_{2}\right)$, c)A3 (30 g/L NaPO $\left.2 \mathrm{H}_{2}\right)$, d)A4 (40 g/L NaPO$\left.{ }_{2} \mathrm{H}_{2}\right)$ ve e)A5 (50 $\left.\mathrm{g} / \mathrm{L} \mathrm{NaPO} \mathrm{H}_{2}\right)$

Şekil 3'de (A1) numunesinde yaklaşık olarak $5 \mu \mathrm{m}$ 'lik bir kaplama kalınlığı elde edilmiştir. Fakat kaplama banyosundaki sodyum hipofosfit oranın artmasıyla kaplama kalınlığı önemli bir ölçüde artış göstermektedir ve en homojen kaplama (A4) ve (A5) numunesinde elde edilmektedir.
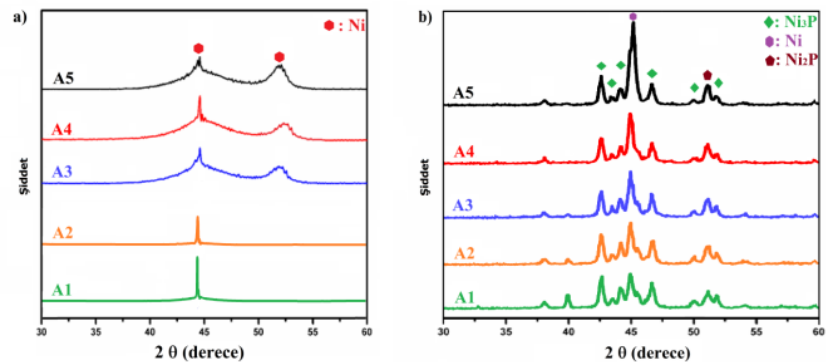

Şekil 4. Akımsız Ni-P kaplamalarda kaplama banyosunda farklı miktarlarda sodyum hipofosfit oranının incelendiği numunelere ait XRD verileri a) 1sıl işlem öncesi ve b) 1sıl işlem sonrası

Şekil 4'de akımsız Ni-P kaplanmış numunelere ait XRD verileri verilmiştir. Kaplamada fosfor oranının artmasından dolayı latiste oluşan düzensizlik kristalin fazdan daha amorf faza doğru değişime (Şekil 4a) sebep olmaktadır. M.Czagánya ve arkadaşları sodyum hipofosfit içeriğinin artmasıyla kaplamanın amorf yapıda oluşacağını savunmuşlardır [11,12]. Fosfor oranıyla birlikte piklerin daha yayvanlaştığı görülmektedir. XRD piklerinde sodyum hipofosfit oranı azaldıkça piklerin şiddeti artmakta ve FWHM daralmaktadir. $\mathrm{Bu}$ durum genel olarak tane boyutunun azaldı $\breve{g}_{1}$ ve kristalinitenin arttığına yorumlanmaktadır. Şekil 4 (a)'ya baktığımız zaman nikele ait piklerin (111) yönünde ve (200) yönünde olduğu görülmektedir. Isıl işlem uygulanmamış yapılar incelendiğinde, amorf yapının varlığı ve bu yapıdaki yüksek şiddetli olarak yer alan (111) yönündeki Ni piki, kaplamadaki baskın yönelmenin [111] doğrultusunda olduğunu göstermektedir. $\mathrm{Bu}$ da sik1 paket (111) düzlemlerinin numune yüzeyine paralel şekilde yer aldığı 
anlamı taşımaktadır. Kaplama banyosunda sodyum hipofosfit miktarının artmasıyla; kaplama bünyesindeki fosfor içeriği artması büyümenin (111) yönünde oluşmasını tetiklediği ve (111) yönündeki büyümenin diğer yönlere göre daha düşük bir gerilme olduğunu söylemiştir. A3 numunesinden sonra (200) yönünde bir izlenim gerçekleşmiştir. En düşük fosfor oranına sahip olan numunede (A1) 440' de $\mathrm{Ni}$ (111) düzlemine ait pik gözükmektedir. $30 \mathrm{~g} / \mathrm{L} \mathrm{NaPO}_{2} \mathrm{H}_{2}$ (sodyum hipofosfit) içeren numunede (A3), kaplamanın kristalin veya mikro kristalin ve amorf fazların karışımını şeklinde pikler içermektedir. 50 $\mathrm{g} / \mathrm{L} \mathrm{NaPO}_{2} \mathrm{H}_{2}$ oranına sahip numunede (A5) ise kaplamadaki en yüksek fosfor oranı bulunmakta (bkn Şekil 2) olmasına ragmen Şekil 4a daki X-ray eğrisinde herhangi bir pik gözükmemektedir. Bu da yapının tamamen amorf olduğunu göstermektedir [12]. Isıl işlem sonrasında kaplamalarda bulunan amorfluk ortadan kalkmakta ve tamamiyla kristalin fazlar elde edilmektedir. Isıl işlem sonrasında ana matris nikel $\left(44^{\circ}, 54^{\circ}\right)$ haricinde $\mathrm{Ni}_{2} \mathrm{P}\left(51^{\circ}\right), \mathrm{Ni}_{3} \mathrm{P}\left(36^{\circ}, 38^{\circ}, 42^{\circ}, 43^{\circ}\right.$, $\left.46^{\circ}, 49^{\circ}, 52^{\circ}\right)$ gibi ikincil fazlar oluşmaktadır [13].

Sertlik testleri daha önceden kesitten bakalit yardımıyla hazırlanan numunelerde akımsız Ni-P kaplamalarda fosfor oranının ve 1 sıl işlemin etkisini incelemek adına, $400{ }^{\circ} \mathrm{C}$ 'de argon-hidrojen koruyucu atmosferinde 2 saat boyunca 1 s1l işleme tabi tutulmuş farklı fosfor oranına sahip kaplamaların sertlik değerleri Vickers cinsinden Şekil 5'de verilmiştir.

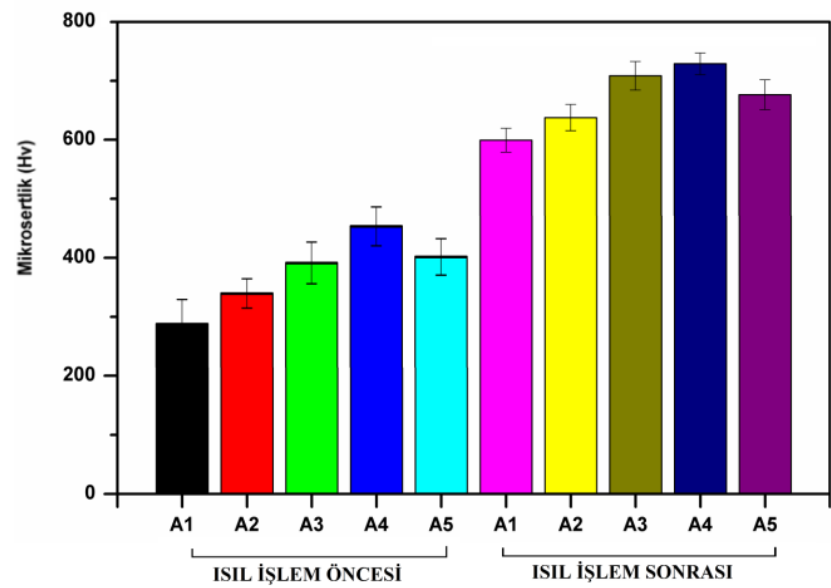

Şekil 5. Sodyum hipofosfit miktarına bağlı olarak elde edilen akımsız Ni-P kaplı numunelere ait 1sıl işlem öncesi ve sonrası sertlik değerleri

Şekil 5'de gözüktüğü gibi 1sıl işleme tabi tutulmuş kaplamaların sertlikleri ısıl işlem görmemiş numunelere göre oldukça yüksektir. Czagánya ve arkadaşları çalışmalarında artan sodium hipofosfit oranıyla birlikte 1sıl işlem sonrası kaplamaların sertliğinin arttığını bulmuştur. Isıl işlemden sonra, sertliğin, sert $\mathrm{Ni}_{3} \mathrm{P}$ fazının artmasıyla birlikte oluştuğunu söylemektedirler [13]. Sertlikteki bu artış, 1sıl işlem ile birlikte düşük sodyum hipofosfit oranına sahip kaplamalarda oluşan kristalin $\mathrm{Ni3P}, \mathrm{Ni}_{2} \mathrm{P}$ vb. bileşiklerin oranı az olduğundan sertlikler daha düşük çıkmıştır. Yüksek elementel fosfor oranına sahip kaplamalarda yapılan isıl işlem ile yapıda oluşan seramik özellikli $\mathrm{Ni}_{2} \mathrm{P}, \mathrm{Ni}_{3} \mathrm{P}$ gibi intermetalik fazlarının daha fazla oluşmasından dolayı bu kaplamalarda sertlik değerleri daha yüksek olarak elde edilmiştir. Kaplamadaki P un belli bir orandan daha fazla artması ile sertlikte bir artışın devam etmediği de gözükmektedir.

\subsection{Akımsız Ni-P Kaplamalarda Kaplama Banyosu Sıcaklığının Etkisi}

Akımsız Ni-P kaplamalarda kaplama banyosu sıcaklığının kaplamalar üzerine etkisi incelenmiş olup banyo bileşimi Tablo 2'de verilmektedir. Kaplama banyosu sıcaklığının artışıyla birlikte kaplamalarda meydana gelen morfolojik değişimler, kaplama kalınlığında ve elementel $\mathrm{Ni}$ ve $\mathrm{P}$ oranındaki değişimler SEM yardımıyla, ısıl işlem öncesi kristalinite/amorfluk durumu ve 1sıl işlem sonrası değişimler ise XRD yardımıyla incelenmiştir. Kaplamaların sertlik özelliklerine de bakılarak optimum kaplama banyosu sıcaklığı tespit edilmeye çalışılmıştır.

Tablo 2. Akımsız Ni-P kaplamalarda kaplama banyosu sıcaklığının etkisinin incelendiği kaplama banyolara ait banyo bileşimleri ve çalışma koşulları

\begin{tabular}{|l|c|c|c|}
\hline Banyo Bileşenleri & B1 & B2 & B3 \\
\hline $\begin{array}{l}\mathrm{NiSO}_{4} \cdot 6 \mathrm{H}_{2} \mathrm{O} \\
(\mathrm{g} / \mathrm{L})\end{array}$ & 28 & 28 & 28 \\
\hline $\mathrm{NaPO}_{2} \mathrm{H}_{2}(\mathrm{~g} / \mathrm{L})$ & 30 & 30 & 30 \\
\hline $\mathrm{C}_{2} \mathrm{H}_{3} \mathrm{NaO}_{2}(\mathrm{~g} / \mathrm{L})$ & 35 & 35 & 35 \\
\hline $\mathrm{C}_{3} \mathrm{H}_{6} \mathrm{O}_{3}(\mathrm{ml} / \mathrm{L})$ & 20 & 20 & 20 \\
\hline $\mathrm{pH}$ & $4-5$ & $4-5$ & $4-5$ \\
\hline Süre $(\mathrm{dk})$ & 30 & 30 & 30 \\
\hline Sicaklık $\left({ }^{\circ} \mathrm{C}\right)$ & $\mathbf{7 0}$ & $\mathbf{8 0}$ & $\mathbf{9 0}$ \\
\hline
\end{tabular}

Şekil 6'da akımsız Ni-P kaplamaların kaplama banyosu sıcaklığına bağlı olarak SEM görüntüleri verilmektedir. Şekilde de görüldüğü gibi sıcaklık arttıkça tane sınırları iyice azalmıştır. (B1) numunesinde kaba nikel taneler gözükürken (B3) numunesine doğru amorflaşma görülmektedir.
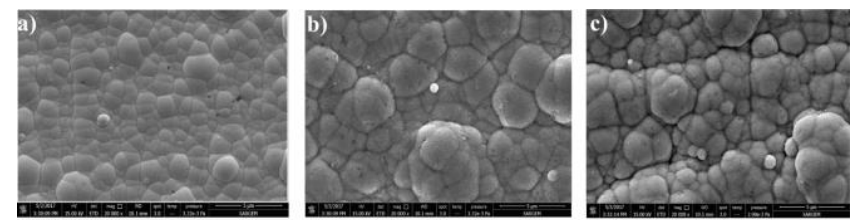

Şekil 6. Farklı sıcaklıklardaki akımsız Ni-P kaplama banyolarından elde edilen numunelere ait yüzey morfolojilerinin SEM görüntüleri a) B1 $\left(70^{\circ} \mathrm{C}\right)$, b) B2 $\left(80^{\circ} \mathrm{C}\right)$ ve c) $\mathrm{B} 3\left(90^{\circ} \mathrm{C}\right)$

Kaplama banyosunun sıcaklığının etkisi Şekil 7 de görülmekte olup, sıcaklık arttıkça kaplama kaplama kalınlığı da artmaktadır. Bununla birlikte aynı fosfor içerikli (çeşitli kaplama sicaklıklarında), nikel kaplamaların kristalleştirilmesi, sıvı alaşımlarının katılaşmasına benzer bir mekanizma ile meydana gelir. $\mathrm{Bu}$ da fosfor içeriğinin artmasına neden olmaktadır [14]. Benzer durum Şekil 8'de de açıkça görüldüğü üzere mevcut olup, artan sıcaklıkla P \% 
si artmaktadır [5]. $90^{\circ} \mathrm{C}^{\prime}$ lik kaplama banyosunda bir saatlik kaplama sonucunda elde edilen numunede (B3 numunesi) yaklaşık olarak $17 \mu \mathrm{m}$ 'lik bir kalınlık elde edilmişstir.
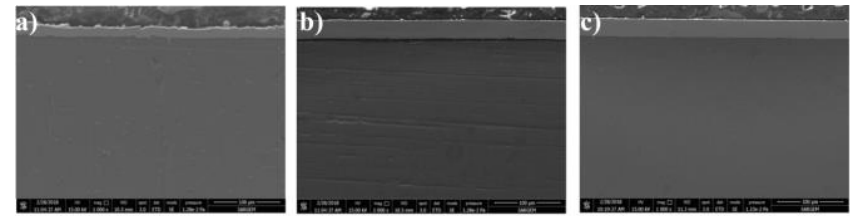

Şekil 7. Akımsız Ni-P kaplamalarda farklı sıcaklıklardaki kaplama banyolarından elde edilen numunelere ait kesit görüntüleri a) $\mathrm{B} 1\left(70^{\circ} \mathrm{C}\right)$, b) $\mathrm{B} 2\left(80^{\circ} \mathrm{C}\right)$ ve c) $\mathrm{B} 3\left(90^{\circ} \mathrm{C}\right)$

Farklı sıcaklıklarda elde edilen akımsız Ni-P kaplama tabakasındaki \% $\mathrm{Ni}$ ve $\% \quad \mathrm{P}$ içeriklerinin sıcaklıkla değişimine ait EDS analiz değerleri Şekil 8 de verilmiştir.

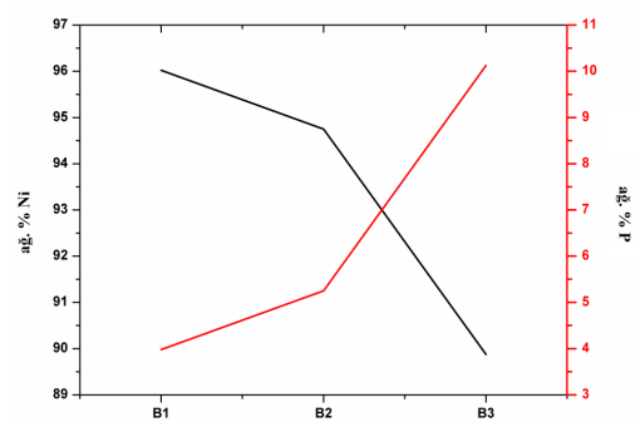

Şekil 8. Farklı sıcaklıklarda elde edilen akımsız Ni-P kaplamalara ait EDS analizi.

Şekil 8 den görüldüğü gibi kaplama banyosunun sıcaklığının artmasıyla kaplama içinde biriken ağırlıkça elementel \% $\mathrm{P}$ oranı artmaktadır. Nikel \% si ise kaplama sıcaklığı ile azalmaktadır. Daha yüksek P içeriği isteniyorsa daha yüksek sıcaklıklarda kaplama yapılması gerektiği ortaya çıkmaktadır.

Şekil 9'da farklı sıcaklıklardaki kaplama banyolarından elde edilen numunelerin 1sıl işlem öncesi ve sonrası XRD sonuçları verilmiştir.
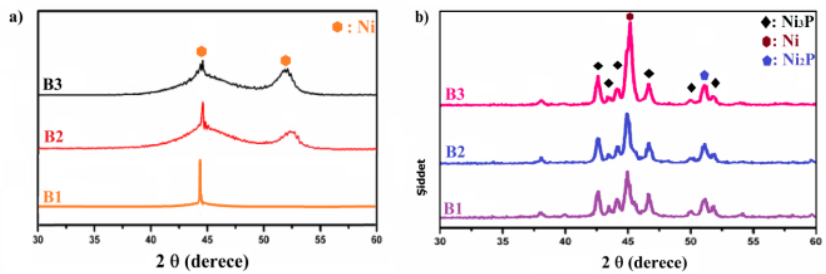

Şekil 9. Akımsız Ni-P kaplamalarda farklı sıcaklıklardaki kaplama banyolarından elde edilen numunelere ait XRD verileri a) 1sıl işlem öncesi ve b) 1sıl işlem sonrası

Şekil 9a'ya bakıldığında kaplama banyosu sıcaklığg $70{ }^{\circ} \mathrm{C}$ 'de elde edilen B1 numunesinin yapısı kristalin bir yapıda iken, sıcaklığın $90 \quad{ }^{0} C^{\prime}$ ye çıkarılmasıyla elde edilen B3 numunesinin 1 sıl işlem öncesi X-1şını kırınım örgüsünde $44^{\circ}$ ortaya çıkan pik, yapının amorfa doğru gittiğini göstermektedir. $\mathrm{Bu}$ da kaplama banyosunun sıcaklığının artmasıyla kaplamaya giren ağırlıkça elementel \%P oranının arttığını ve yapının bundan dolayı daha amorf bir hal aldığı söyleyenebilir [15]. Şekil 9b ise farklı kaplama banyosu sıcaklıklarında elde edilen numunelerin isıl işlem sonrası XRD eğrileri verilmiştir. Görüldüğü üzere, 1sıl işlem uygulanmasıyla $\mathrm{Ni}$ matrisin içinde nikelin yanı sıra $\mathrm{Ni}_{2} \mathrm{P}$ ve $\mathrm{Ni}_{3} \mathrm{P}$ çökelti fazlarının oluştuğu görülmektedir. Özellikle

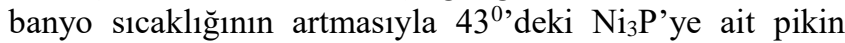
şiddetinin arttı̆̆ gözlemlenmektedir. Banyo sıcaklığının artmasıyla kaplama içindeki ağırlıkça elementel \% $\mathrm{P}$ miktarının artması daha fazla $\mathrm{Ni}_{3} \mathrm{P}$ fazının çökmesine neden olmaktadır.

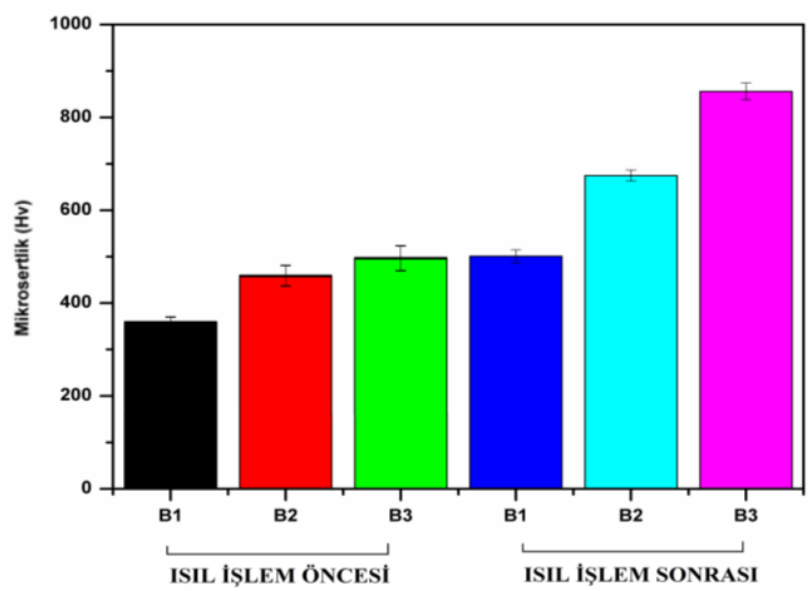

Şekil 10. Akımsız Ni-P kaplamalarda farklı sıcaklıklardaki kaplama banyolarından elde edilen numunelere ait isıl işlem öncesi ve sonrası sertlik değerleri

Şekil 10'da akımsız Ni-P kaplamaların 1sıl işlem öncesi ve sonrası sertlikleri görülmektedir. Sıcaklık artışına bağlı olarak kaplamanın kesitinin daha kalın hale gelmesi yanında tabakada $\mathrm{Ni}_{2} \mathrm{P}, \mathrm{Ni}_{3} \mathrm{P}$ gibi sert fazların oluşumundan dolayı sertlik artmaktadır.

\subsection{Akımsız Ni-P Kaplamalarda Kaplama Süresinin Etkisi}
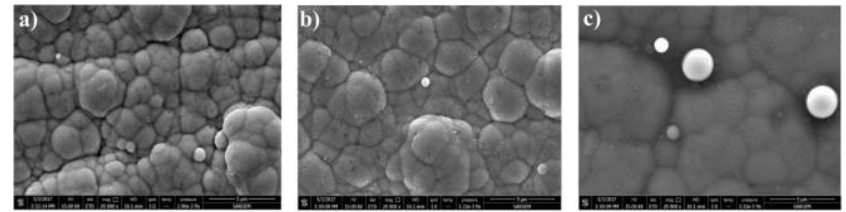

Şekil 11. Farklı kaplama sürelerinde elde edilen akımsız NiP kaplamaların SEM görüntüsü a) C1 (30 dk), b) C2 (60 dk) ve c) C3 (90 dk)

Akımsız Ni-P kaplamalarda kaplama süresinin, kaplamalar üzerindeki etkisi incelenmiş olup Tablo 3 'de banyo bileşimi ve çalışma koşulları verilmektedir. 
Tablo 3. Ni-P kaplamalarda kaplama süresinin etkisinin incelendiği banyoların bileşenleri ve çalışma koşulları

\begin{tabular}{|l|c|c|c|}
\hline Banyo Bileşenleri & C1 & C2 & C3 \\
\hline $\begin{array}{l}\mathrm{NiSO}_{4} \cdot 6 \mathrm{H}_{2} \mathrm{O} \\
(\mathrm{g} / \mathrm{L})\end{array}$ & 28 & 28 & 28 \\
\hline $\mathrm{NaPO}_{2} \mathrm{H}_{2}(\mathrm{~g} / \mathrm{L})$ & 30 & 30 & 30 \\
\hline $\mathrm{C}_{2} \mathrm{H}_{3} \mathrm{NaO}_{2}(\mathrm{~g} / \mathrm{L})$ & 35 & 35 & 35 \\
\hline $\mathrm{C}_{3} \mathrm{H}_{6} \mathrm{O}_{3}(\mathrm{ml} / \mathrm{L})$ & 20 & 20 & 20 \\
\hline $\mathrm{pH}$ & $4-5$ & $4-5$ & $4-5$ \\
\hline Süre $(d k)$ & $\mathbf{3 0}$ & $\mathbf{6 0}$ & $\mathbf{9 0}$ \\
\hline Sicaklık $\left({ }^{\circ} \mathrm{C}\right)$ & 90 & 90 & 90 \\
\hline
\end{tabular}
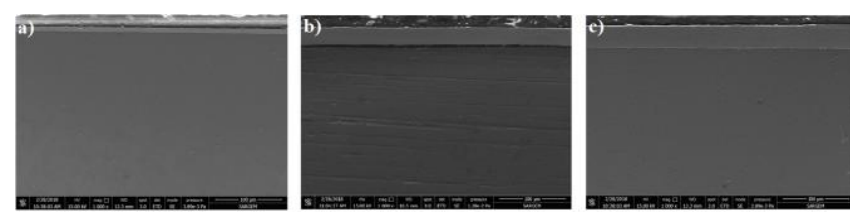

Şekil 12. Farklı kaplama sürelerinde elde edilen akımsız NiP kaplamalara ait kesit görüntüsü a) C1, b) C2 ve c) C3 (90 $\mathrm{dk})$

Şekil 12'de farklı kaplama sürelerinde elde edilen kaplamaların kesit görüntüleri görülmektedir. En uzun kaplama süresine (90 dk) sahip olan (C3) kaplamasında 25 $\mu \mathrm{m}$ kaplama kalınlığı elde edilirken, (C1) numunesinde ise kaplama kalınlığı $10 \mu$ m'dir [16]. Ayrıca sıcaklık $90 \mathrm{C}$ de en iyi verim alındığından, bu sicaklıkta redüksiyon hızı da arttığından dolayı kaplama hızı ve kalınlığı artmaktadır. Bu durumda hem nikelin hem de $\mathrm{P}$ un redüklenmesi söz konusu olmasına rağmen, Şekil 13'e bakıldığında kaplama içerisindeki P oranının daha fazla olması, P redüksiyon hızının daha fazla olduğunu da ortaya koymuştur.

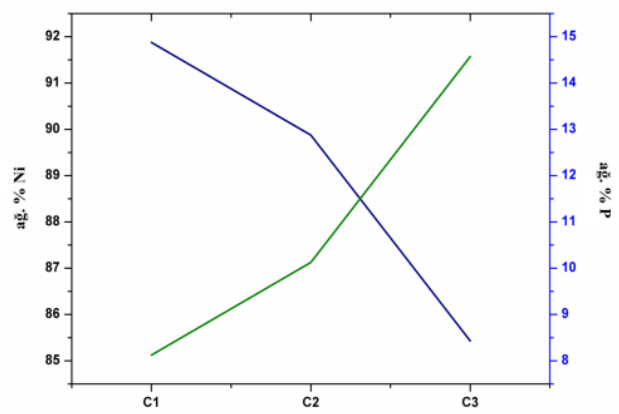

Şekil 13. Farklı kaplama sürelerinin kaplamalardaki $\% \mathrm{Ni}$ ve \% değişimine etkisi (EDS analizi) $(\mathrm{C} 1: 30 \mathrm{dk}, \mathrm{C} 2: 60 \mathrm{dk}$, C3: $90 \mathrm{dk}$ )

Şekil 14'de farklı kaplama sürelerine sahip akımsız Ni-P kaplamaların 1 sıl işlem öncesi ve sonrası X-ray pikleri görülmektedir. Isıl işlem öncesinde her üç numune için de piklerin artan zamana bağlı olarak daha da yayvanlaşmakta ve amorf yapılar gözükmektedir. Isıl işlem sonrasında zaman arttıkça kaplama içerisinde ağırlıkça P oranının artmasıyla birlikte $44^{\circ}$ pikin daha dik ve yüksek şiddete sahip olduğu anlaşılmaktadır. P un etkisiyle oluşan amorf yapıların 1sıl işlemle kristalize olduğu, nikelin yanında ayrıca $\mathrm{Ni}_{2} \mathrm{P}$ ve $\mathrm{Ni}_{3} \mathrm{P}$ kristalin fazlarının oluştuğu, en yüksek şiddete dolayısıyla fazla kristaliniteye $90 \mathrm{dk}$ lık sürede ulaşıldığ anlaşılmaktadır.
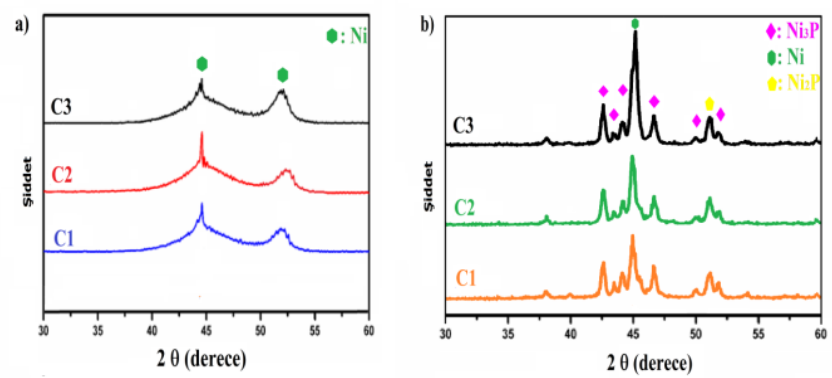

Şekil 14. Akımsız Ni-P kaplama süresinin kristaliniteye etkisi (XRD eğrileri) a) 1sıl işlem öncesi b) 1sıl işlem sonrası

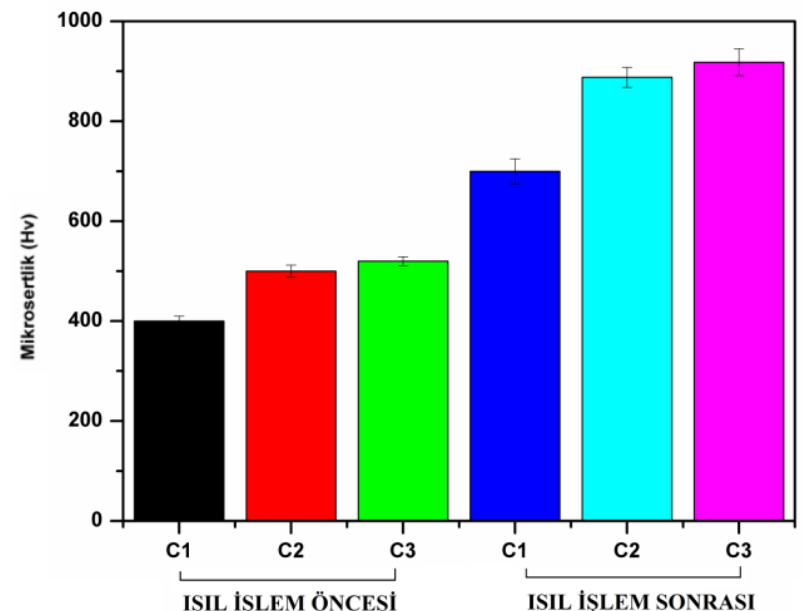

Şekil 15. Farklı kaplama sürelerinin sertliğe etkisi a) 1sıl işlem öncesi, b) 1sıl işlem sonrası

Şekil 15'de akımsız Ni-P kaplamaların 1sıl işlem öncesi ve sonrası sertlik değerleri verilmektedir. Şekle göre en yüksek sertliğe sahip olan Ni-P kaplaması 90 dk kaplama (C3) yapılan numunede elde edilmiştir. Burada sertlik değeri yaklaşık olarak 1sıl işlem öncesi 512 HV iken, 1sıl işlem sonrası 950 HV'e kadar çıkmaktadır. Sertlik değerinin artışı $\mathrm{Ni}_{2} \mathrm{P}, \mathrm{Ni}_{3} \mathrm{P}$ seramik özellikli fazların oluşumu nedeniyle olmaktadir [16].

\section{SONUÇLAR}

Akımsız Ni-P kaplamalar başarı ile üretilmiş ve bu kaplama çalışmalarına indirgeyici konsantrasyonunun (sodyum hipofosfit) artmasıyla kaplama tabakasındaki \%P oranı artmış, 1sıl işlem uygulanmamış numunede amorf yapı baskınken 1sıl işlem sonrası $\mathrm{Ni}_{3} \mathrm{P}$ ve $\mathrm{Ni}_{2} \mathrm{P}$ kristalin fazlarının artışına bağlı olarak sertlikte de artış gözlenmiştir.

Kaplama banyosu sıcaklığının artışına bağlı olarak \%P oranı, kaplama kalınlığı ve amorflaşma da artmıştır. Isıl işlem sonrası kristalinite artmış ve sertlikte ciddi artışlar meydana gelmiştir.

Kaplama süresinin artışıyla tabakadaki \%P oranı, amorflaşma ve kaplama kalınlığı artmıştır. Kaplamalara ısıl 
işlem uygulandığında seramik esasl $\mathrm{Ni}_{2} \mathrm{P}$ ve $\mathrm{Ni}_{3} \mathrm{P}$ bileşikleri teşekkül etmiştir. Kaplamda en yüksek sertliğe 90 dakikalık sürede ulaşılmış olup, 950 Vikers sertliklere ulaşılmıştır.

Çevre ve sağlık açısından zararlı $\mathrm{Cr}^{+6}$ banyosundan hareketle elde edilen $\mathrm{Cr}$ kaplamaların sertliğinin 850-1000 Vikers civarında olduğu düşünüldüğünde, çevresel açıdan daha olan pozitif akımsız banyolar aracılığıyla 950 Vikers serliğe ulaşılması son derece önemlidir. Üstelik çevresel ve sağlık problemlerinden kaynaklı maliyetler de söz konusu olmayacak demektir.

\section{TEŞEKKÜR}

Bu çalışma, Tübitak'ın 1005 çerçevesinde desteklediği 116M998 Nolu proje sonuçlarından hazırlanmıştır.

\section{KAYNAKÇA}

[1] R. C. Özden, "Sicak Haddelenmiş AZ91 Magnezyum Alaşımı Üzerine Uygulanan Akımsız Ni-P-W Kaplamanın Korozyon ve Aşınma Özellikleri," Eskişehir Osmangazi Üniversitesi, 2015.

[2] P. Sampath Kumar and P. Kesavan Nair, "Studies on crystallization of electroless Ni-P deposits," J. Mater. Process. Technol., vol. 56, no. 1-4, pp. 511-520, 1996.

[3] D. Gökçe, “Akımsız Nikel Fosfor/nikel Bor Dubleks Kaplamaların Korozyon Ve Aşınma Dirençlerinin İncelenmesi," İstanbul Teknik Üniversitesi, 2012.

[4] J. Sudagar, J. Lian, and W. Sha, "Electroless nickel, alloy, composite and nano coatings - A critical review," Journal of Alloys and Compounds, vol. 571. pp. 183-204, 2013.

[5] A. I. Aydeniz, A. Göksenli, G. Dil, F. Muhaffel, C. Calli, and B. Yüksel, "Electroless ni-b-w coatings for improving hardness, wear and corrosion resistance," Mater. Tehnol., vol. 47, no. 6, pp. 803-806, 2013.

[6] S. K. Das and S. Prasamta, "A parametric investigation of the friction performance of electroless Ni-B coatings," Lubr. Sci., vol. 23, pp. 81-97, 2011.

[7] K. N. Srinivasan, R. Meenakshi, A. Santhi, P. R. Thangavelu, and S. John, "Studies on development of electroless $\mathrm{Ni}-\mathrm{B}$ bath for corrosion resistance and wear resistance applications," Surf. Eng., vol. 26, no. 3, pp. 153 $158,2010$.

[8] S. K. Das and P. Sahoo, "Tribological characteristics of electroless Ni-B coating and optimization of coating parameters using Taguchi based grey relational analysis," Mater. Des., vol. 32, no. 4, pp. 2228-2238, 2011.

[9] P. G. Venkatakrishnan, S. S. Mohamed Nazirudeen, and T. S. N. Sankara Narayanan, "Formation and Structural Characterization of Electroless Ni-B-P Ternary Alloy Coatings," Appl. Mech. Mater., vol. 592-594, pp. 385-390, 2014.

[10] A. Zarebidaki and S. R. Allahkaram, "Effect of surfactant on the fabrication and characterization of Ni-PCNT composite coatings," J. Alloys Compd., vol. 509, no. 5, pp. 1836-1840, 2011.

[11] R. Taheri, "Evaluation of Electroless NickelPhosphorus ( EN ) Coatings," PhD Thesis, no. August 2002, p. 229, 2003.

[12] M. Czagány, P. Baumli, and G. Kaptay, "The influence of the phosphorous content and heat treatment on the nano-micro-structure, thickness and micro-hardness of electroless Ni-P coatings on steel," Appl. Surf. Sci., vol. 423, pp. 160-169, 2017.

[13] T. S. N. Sankara Narayanan, I. Baskaran, K. Krishnaveni, and S. Parthiban, "Deposition of electroless Ni$\mathrm{P}$ graded coatings and evaluation of their corrosion resistance," Surf. Coatings Technol, vol. 200, no. 11, pp. 3438-3445, 2006.

[14] H. Ashassi-Sorkhabi and S. H. Rafizadeh, "Effect of coating time and heat treatment on structures and corrosion characteristics of electroless Ni-P alloy deposits," Surf. Coatings Technol., vol. 176, pp. 318-326, 2004.

[15] M. Yan, H. G. Ying, and T. Y. Ma, "Improved microhardness and wear resistance of the as-deposited electroless Ni-P coating," Surf. Coatings Technol., vol. 202, no. 24, pp. 5909-5913, 2008.

[16] M. Anik and G. Celikten, "Analysis of the electrochemical reaction behavior of alloy AZ91 by EIS technique in $\mathrm{H} 3 \mathrm{PO} 4 / \mathrm{KOH}$ buffered K2SO4 solutions," Corros. Sci., vol. 49, no. 4, pp. 1878-1894, 2007. 